\title{
Cost, Utilization, and Quality of Care: An Evaluation of Illinois' Medicaid Primary Care Case Management Program
}

\author{
Robert L. Pbillips Jr, MD, MSPH \\ Meiying Han, $\mathrm{PbD}^{2,3}$ \\ Stephen M. Petterson, $\mathrm{PbD}^{3}$ \\ Laura Makaroff, DO ${ }^{4}$ \\ Winston R. Liaw, MD, MPH ${ }^{5}$ \\ ${ }^{1}$ American Board of Family Medicine, \\ Washington, DC \\ ${ }^{2}$ Goleta, California \\ ${ }^{3}$ The Robert Graham Center, \\ Washington, DC \\ ${ }^{4}$ Health Resources and Services Adminis- \\ tration, Bureau of Health Professions, \\ Rockville, Maryland \\ ${ }^{5}$ Department of Family Medicine, \\ Virginia Commonwealth University, \\ Fairfax, Virginia
}

\begin{abstract}
PURPOSE In 2006, Illinois established Illinois Health Connect (IHC), a primary care case management program for Medicaid that offered enhanced fee-forservice, capitation payments, performance incentives, and practice support. Illinois also implemented a complementary disease management program, Your Healthcare Plus (YHP). This external evaluation explored outcomes associated with these programs.
\end{abstract}

METHODS We analyzed Medicaid claims and enrollment data from 2004 to 2010, covering both pre- and post-implementation. The base year was 2006, and 2006-2010 eligibility criteria were applied to 2004-2005 data to allow comparison. We studied costs and utilization trends, overall and by service and setting. We studied quality by incorporating Healthcare Effectiveness Data and Information Set (HEDIS) measures and IHC performance payment criteria.

RESULTS Illinois Medicaid expanded considerably between 2006 (2,095,699 fullyear equivalents) and $2010(2,692,123)$. Annual savings were $6.5 \%$ for $\mathrm{IHC}$ and $8.6 \%$ for YHP by the fourth year, with cumulative Medicaid savings of $\$ 1.46$ billion. Per-beneficiary annual costs fell in Illinois over this period compared to those in states with similar Medicaid programs. Quality improved for nearly all metrics under IHC, and most prevention measures more than doubled in frequency. Medicaid inpatient costs fell by $30.3 \%$, and outpatient costs rose by $24.9 \%$ to $45.7 \%$ across programs. Avoidable hospitalizations fell by $16.8 \%$ for YHP, and bed-days fell by $15.6 \%$ for IHC. Emergency department visits declined by $5 \%$ by 2010 .

CONCLUSIONS The Illinois Medicaid IHC and YHP programs were associated with substantial savings, reductions in inpatient and emergency care, and improvements in quality measures. This experience is not typical of other states implementing some, but not all, of these same policies. Although specific features of the Illinois reforms may have accounted for its better outcomes, the limited evaluation design calls for caution in making causal inferences.

Ann Fam Med 2014;12:408-417. doi: 10.1370/afm.1690.

\section{INTRODUCTION}

A consent decree in the case of Memisovski v. Maram (2004) ruled that Illinois had violated federal law by not providing adequate access to primary care services for its Medicaid population. ${ }^{1}$ This suit made Illinois an early leader in comprehensive Medicaid reform, eventually producing 2 programs, Illinois Health Connect (IHC) and Your Healthcare Plus (YHP). IHC, a primary care case management program, aimed to promote preventive care and reduce redundancy of services through continuity of care with a primary care provider for patients who were not "dual eligible"; that is, patients who were not eligible for both Medicare and Medicaid benefits. YHP was a disease management program, nearly all of whose members were also in IHC. These programs ultimately served more than two-thirds of all eligible Medicaid beneficiaries and $15 \%$ of the total state population. Analyses by state officials suggested that these programs saved $\$ 180$ million in 2008 and $\$ 320$ million in 2009 compared to prior years. ${ }^{2}$
Robert L. Phillips Jr, MD, MSPH Vice President for Research \& Policy American Board of Family Medicine 1133 Connecticut Ave, NW Suite 1100 Washington, DC 20036 bphillips@theabfm.org 
This study aimed to analyze the Illinois Medicaid experiment; specifically to understand whether IHC and YHP were associated with reduced inappropriate utilization, reduced costs, or improved delivery of appropriate preventive and chronic care between 2006 and 2010. We also evaluated total Medicaid cost and utilization changes.

Many states are developing approaches that strengthen primary care with the goal of improving quality and lowering Medicaid costs. The patientcentered medical home (PCMH) is considered a promising model, and 41 states have launched or plan to launch demonstrations based on this model. ${ }^{3}$ In 2008, Weil raised the concern that "very few state health policy changes are studied using experimental method," with the result that "diffusion of policy innovations is slow and sometimes does not occur at all."4 Single-state experiences can hold lessons for others, since many are in the middle of time-sensitive demonstrations. ${ }^{5-10}$ They also beg for thoughtful policy implementation to allow better evaluation.

\section{BACKGROUND}

\section{Program Description}

Illinois Health Connect was implemented in 2006 to extend the primary care case management approach developed in smaller demonstration programs. Primary care case management includes many elements of the $\mathrm{PCMH}$, as defined by the Patient-Centered Primary Care Collaborative and the US Agency for Healthcare Research and Quality. ${ }_{11,12}$ Automated Health Systems administered IHC through a contract with the Illinois Department of Health and Family Services (HFS). Implementation of IHC and YHP preceded most PCMH certification standards, but the related contractual requirements and blended payments resemble arrangements recommended for PCMHs. For example, in addition to fee-for-service payments, providers received monthly perpatient payments and substantial bonuses for meeting quality thresholds (Table 1 ). ${ }^{11}$

In addition, IHC provided other supportive services including patient registries, referral and care-coordination support, quality improvement tools, access to Medicaid claims databases (including prescription fills), and physician quality measure profiles. We don't know how practices spent their care management fees, but the IHC team observed that clinicians generally felt that they made low Medicaid rates more palatable and that, for some physicians, they created a sense of obligation to provide services outside of normal patient visits because they were paid on a per-patient basis (personal communication, Dr Margaret Kirkegaard, Medical Director, Illinois Health Connect, Automated Health Systems). Online quality report cards in each physician's IHC portal featured not only the physician's quality measures, but how the physician compared to a peer benchmark, how much he or she had received in bonus payments, and how much bonus he or she could have earned if the measures had been better. Patient registries and claims histories (including visits to other providers or settings) in the IHC physician portal were populated by IHC for use by IHC providers. A physician satisfaction survey from 2012 (31\% response rate) found the following:

- $80.2 \%$ agreed or strongly agreed that the IHC Panel Roster helped them manage patients' care $(12.2 \%$ reported not using it).

- $67.3 \%$ agreed or strongly agreed that the IHC Provider Portal provided useful tools such as Claims History and online Panel Rosters (25.3\% reported not using them).

- $81.9 \%$ agreed or strongly agreed that the mailed Provider Profiles, which featured physicians' quality measures, were useful for quality improvement (10.7\% had not seen them).

- $75.2 \%$ agreed or strongly agreed that the bonus payment program stimulated quality improvement in their practice (10.6\% were unaware of the bonus program).

- $36.6 \%$ agreed or strongly agreed that the IHC Quality Assurance Nurse (academic detailing) service was helpful for understanding their Profile quality measures and how to achieve maximum bonus

\section{Table 1. Features of Illinois Health Connect}

1.7 Million beneficiaries in 2010 (includes YHP patients in IHC); every beneficiary required to select a primary care clinician ${ }^{a}$

Monthly care management fees: $\$ 2$ for children, $\$ 3$ for adults, $\$ 4$ for disabled or elderly beneficiaries ${ }^{a}$

Pediatric claims paid within 30 days; adult claims paid within 60 days

Quarterly academic detailing about the administration of the program and clinical care of the patient population for primary care clinicians

Multiple online tools such as registries and report cards to assist clinicians with population-based management ${ }^{\mathrm{b}}$

IHC providers required to make preventive care available within 5 weeks of request (or 2 weeks for infants younger than 6 months), urgent care appointments within 24 hours, appointments for non-serious complaints within 3 weeks, and follow-up visits within 7 days of discharge from an emergency department or hospitala Practices required to provide and coordinate maternal and child health services ${ }^{a}$ Practices required to institute an action plan for enrollees with chronic diseases ${ }^{a}$ Quality-based bonus payments ${ }^{a}$

$\mathrm{IHC}=$ Illinois Health Connect; YHP = Your Healthcare Plus.

a Features common in patient-centered medical homes.

${ }^{b}$ Features common in accountable care organizations. 
payments (61.8\% had not used the Quality Assurance Nurse service).

- $85.8 \%$ agreed or strongly agreed that they would recommend IHC to their colleagues (2.5\% strongly disagreed).

Eligibility for bonus payments was set at the HEDIS 50th percentile, and in 2011, 4,403 IHC primary care physicians in 4,779 sites (nearly $90 \%$ of those eligible) received bonus payments (IHC internal documents provided by Dr Margaret Kirkegaard). In 2011 , this amounted to $\$ 5,349,900$ in bonus payments. We do not know how IHC operationalized or assessed the required provision and coordination of child health services, nor do we know whether chronic disease action plans were monitored or audited.

Nearly all YHP patients also participated in IHC. McKesson Health Solutions was the contractor for YHP. In 2010, 388,000 beneficiaries were enrolled in YHP. They fell into at least 1 of 4 categories for eligibility: (1) adults with chronic conditions including asthma, diabetes mellitus, chronic obstructive pulmonary disease, coronary artery disease, congestive heart failure, schizophrenia, and depression; (2) children and adults with persistent asthma; (3) high frequency emergency department users; and (4) elderly and physically disabled individuals in Medicaid waiver programs. Just $6 \%$ of YHP long-term care beneficiaries ineligible for Medicare were excluded from analysis.

\section{METHODS}

This analysis used Illinois Medicaid claims and eligibility data from January 1, 2004, to December 31, 2010, covering periods before (2004-2005) and after (20072010) implementation of IHC and YHP, with 2006 as a transitional year. Claims and eligibility data were provided by Illinois HFS. The eligibility file contains beneficiaries' demographic characteristics, program eligibility and enrollment status for each day of a 7-year period. The claims file contains details for all services, including service date, service category, provider, provider type, charges, payments, procedures, and diagnosis codes.

We developed IHC and YHP cohorts based on beneficiaries' eligibility periods. Member months and year-equivalent measures were derived using the beneficiaries' eligible day counts during the corresponding calendar year. We used HFS beneficiary criteria from 2006 to 2010 to identify patients in 2004 and 2005 who would have been eligible for IHC and YHP had the programs existed then, thus creating a pre-implementation comparison cohort. To account for potential bias due to inclusion of all eligible beneficiaries in 2004-2005, we included patients who were not enrolled in IHC but met eligibility criteria in all post-implementation cohorts. Participation in IHC was required for most beneficiaries (except for those in other managed care programs and dual-eligible beneficiaries) so a randomized control group was not available. For the YHP study cohort, we only included enrolled patients, since beneficiaries were given the choice to opt in or out. To be clear, YHP participants are also eligible for IHC, but we present their outcomes separately. We also analyzed utilization and cost outcomes for the whole Illinois Medicaid program.

Across all years, we excluded beneficiaries enrolled in managed care organizations, since their claims did not reflect the fees associated with specific services. The small number of individuals in long-term care who were in YHP but not eligible for IHC were also excluded. Costs and utilization for infants younger than 90 days were excluded because poor birth outcomes may introduce significant fluctuation in costs and utilization unrelated to the primary care case management plan.

For IHC and YHP cohorts, we examined inpatient and outpatient service utilization. We analyzed trends in hospitalization and bed-days per 1,000 beneficiaries. We examined emergency department utilization per 1,000 beneficiaries. An unusual rise in emergency visits between 2009 and 2010 led us to also investigate emergency visit rates associated with the 2009-2010 $\mathrm{H} 1 \mathrm{~N} 1$ influenza epidemic. We used influenza and related diagnosis codes for the latter analysis.

We calculated cost trends by developing permember-per-month (PMPM) costs for each category of service: inpatient, clinical (outpatient), pharmacy, physician, transportation, waivers, long-term care, durable medical equipment, and lab/x-ray. We compared actual costs with projected costs based on a pre-2006 medical inflation rate of $3 \%$, the figure used by Illinois officials in their internal IHC evaluation and based on changes in Medicaid program costs before 2006 (personal communication, HFS). Several sources suggest that this is a conservative reference:

- The Bureau of Labor Statistics' annual consumer price index medical care component was above 3\% for each year from 2004 to 2010, reaching a high of $4.4 \%$ in 2007 and a low of $3.2 \%$ in $2009 .{ }^{13}$

- The Kaiser Family Foundation reports the Illinois annual rate of growth for Medicaid as $8.7 \%$ for 2001-2004 and 7.6\% for 2004-2007; these rates are for the entire Illinois Medicaid population, though, including dual-eligible beneficiaries, whose rate is traditionally higher than that of the rest of the Medicaid population. ${ }^{14}$

- The annual National Health Expenditure analysis found that the Medicaid annual growth for the nation ranged from $7.2 \%-8.9 \%$ between 2007 and $2010^{15}$ 
Based on these sources, a 3\% growth-rate assumption is plausible and conservative. Expenditure changes for YHP and the overall Medicaid program were also assessed against this 3\% growth because neither was the primary focus of this evaluation. This means that savings associated with YHP and overall Medicaid are likely underestimated given the actual inflation rates reported from the Kaiser Family Foundation. We chose to evaluate costs for the overall Medicaid program since many of the dual-eligible patients were also patients of physicians participating in IHC.

In cost/utilization analyses, 2006 was treated as the baseline year. Both pre-implementation (2004, 2005) and post-implementation (2007-2010) comparisons were made with reference to 2006 estimates, and cost and utilization rates were standardized by age, sex, and race distributions to 2006 population data. We evaluated quality of care for IHC enrollees by using measures from both the National Committee for Quality Assurance's Healthcare Effectiveness Data and Information Set (HEDIS) and the IHC incentive payment criteria. We include quality outcomes only for the IHC-enrolled population. Quality measures included the percentages of adults receiving age- and disease-appropriate services:

- cancer screening (mammography, cervical cancer screening, colon cancer screening)

- diagnosis and treatment program services (nephropathy screening, hemoglobin $\mathrm{A}_{1 \mathrm{c}}$ tests and diabetes eye examinations for patients with diabetes, com- plete lipid profiles for patients with ischemic heart disease)

- prescription drug therapies ( $\beta$-blocker for patients with a diagnosis of acute myocardial infarction, asthma controller for qualified patients)

- well-child visits for children

Child immunizations were excluded because of the incomplete immunization data in Medicaid claims. Quality measures were tabulated using full calendar year claims data. The quality measure comparison year was 2007, since 2006 had small enrollment.

Statistical analyses were completed using SAS 9.2 and Stata 12.1. Significance testing was done for quality measures. This study was approved by the AAFP Institutional Review Board, and data exchanges were covered by a Business Associate Agreement with Illinois HFS for HIPAA compliance.

\section{RESULTS}

\section{Beneficiary Population}

The program grew considerably over the study period. In 2006, Illinois Medicaid covered 2,095,699 full-yearequivalent enrollees, of whom 1,454,595 were eligible for the IHC program (including YHP). Study cohort data in Table 2 reflect adjustments for managed care patients, infants younger than 90 days, and institutionalized populations. By 2010, the program had grown to cover 2,692,123 people, of whom 2,012,936 were eligible for IHC (again, including YHP). At that point,

Table 2. Study Cohort Demographics in Illinois Medicaid Programs

\begin{tabular}{|c|c|c|c|c|c|c|c|c|}
\hline & \multicolumn{4}{|c|}{2006} & \multicolumn{4}{|c|}{2010} \\
\hline & Medicaid & IHC-Eligible & YHP-Enrolled & Othera $^{a}$ & Medicaid & IHC-Eligible & YHP-Enrolled & Other $^{\mathrm{a}}$ \\
\hline Beneficiaries, No. b & 2,095,699 & $1,178,192$ & 276,403 & 641,104 & $2,692,123$ & $1,624,370$ & 388,566 & 679,187 \\
\hline \multicolumn{9}{|l|}{ Study cohorts datac } \\
\hline \multicolumn{9}{|l|}{ Age, \% } \\
\hline $0-5 y$ & 19.8 & 27.0 & 20.2 & 7.6 & 19.1 & 25.5 & 17.6 & 6.7 \\
\hline $6-18$ y & 35.5 & 42.9 & 24.7 & 27.6 & 38.3 & 45.8 & 33.5 & 25.6 \\
\hline $19-40$ y & 22.0 & 23.2 & 27.3 & 17.7 & 21.0 & 21.3 & 25.4 & 18.2 \\
\hline $41-64$ y & 14.2 & 5.9 & 27.4 & 22.4 & 14.0 & 6.7 & 23.3 & 23.8 \\
\hline $65+y$ & 8.5 & 0.9 & 0.4 & 24.8 & 7.7 & 0.9 & 0.3 & 25.6 \\
\hline \multicolumn{9}{|l|}{ Race/ethnicity, \% } \\
\hline Non-Hispanic white & 39.9 & 36.4 & 38.1 & 46.6 & 40.5 & 37.3 & 38.7 & 47.9 \\
\hline Non-Hispanic black & 30.7 & 27.7 & 37.7 & 32.9 & 26.1 & 22.0 & 33.3 & 30.5 \\
\hline Hispanic & 20.7 & 26.3 & 17.8 & 12.5 & 24.2 & 30.5 & 21.1 & 13.1 \\
\hline Other raced & 8.6 & 9.6 & 6.5 & 7.9 & 9.2 & 10.2 & 6.9 & 8.5 \\
\hline \multicolumn{9}{|c|}{$\begin{array}{l}\text { a Includes mainly beneficiaries enrolled in both Medicare and Medicaid (the dual } \\
\text { b Beneficiaries after the exclusion of infants younger than } 90 \text { days. } \\
\text { ' Study cohorts after the exclusion of individuals in managed care organizations, in } \\
\text { d Includes Asian, Pacific Islander, etc. }\end{array}$} \\
\hline
\end{tabular}


5,482 primary care physicians participated in IHC. YHP also experienced rapid growth, the number of year-equivalent enrollees having grown from 276,403 in 2006 to 388,566 in 2010 . By $2010,82.9 \%$ of people eligible for IHC (not YHP) were enrolled. A disproportionate share of Medicaid growth between 2006 and 2010 accrued to IHC, which grew from $56.2 \%$ to $60.3 \%$ of beneficiaries. Fewer than $1 \%$ of beneficiaries eligible for YHP opted out. Dual-eligible beneficiaries were not required to participate in IHC and YHP, and patients 65 and older made up just $0.9 \%$ and $0.3 \%$ of IHC and YHP, respectively.

Exclusions noted above reduced our evaluation population to 1,388,134 IHC-eligible individuals and 363,411 YHP enrollees in 2010. The race and ethnicity mix of Medicaid beneficiaries changed significantly over the study period (Table 2), and we adjusted for these in our analyses.

\section{Utilization}

The adjusted hospitalization rate for IHC-eligible beneficiaries was already declining by 2006 , and it continued to fall by $18.1 \%$ between 2006 and 2010 . The adjusted YHP hospitalization rate rose before 2006 but fell $9.7 \%$ by 2010. Between 2006 and 2010, the bed-day rate fell $15.6 \%$ for IHC, $13.4 \%$ for YHP. Avoidable hospitalizations fell $16.8 \%$ for YHP. The adjusted emergency department visit rate declined $5.0 \%$ for IHC and $4.6 \%$ for YHP. The emergency visit rate did rise in 2009, almost entirely due to the H1N1 influenza pandemic, such that 2009 visits for influenza or related symptoms for IHC patients increased by $57.2 \%$ from 2008 numbers. Ignoring influenzaassociated emergency department visits, the 2009 visit rate declined $1.3 \%$ compared to 2008 for IHC beneficiaries. From 2006 to 2010, the overall Medicaid program also realized substantial reductions in hospitalization (15.1\%), bed-day rates (18.6\%) and avoidable hospitalizations (19.4\%).

\section{Costs}

We estimate the gross savings from 2007-2010 to be $\$ 237$ million for IHC, \$518 million for YHP, and \$1.46 billion for Medicaid overall, despite a rise in actual costs for IHC-eligible beneficiaries from $\$ 1.5$ billion in 2006 to $\$ 2.1$ billion in 2010 (Table 3). Estimated savings were initially twice as high but were reduced by adjustments for race and ethnicity changes. The rate of annual PMPM growth in IHC costs decreased slightly from 2004 to 2010, although it was elevated in part by the influenza epidemic, and YHP PMPM costs fell substantially by 2010 (Figure 1). The rate of estimated annual savings increased about $2 \%$ per year to $6.5 \%$ in 2010 for IHC, and increased from $3.5 \%$ in 2007 to $8.6 \%$ in 2010 for YHP enrollees.

The largest savings within all Medicaid programs were due to reductions in inpatient services (Table 4), which fell by $22.7 \%-30.3 \%$ compared to projections. Costs rose in key areas for IHC such as outpatient clinic services (45.7\%), largely as a result of planned payment changes.

\section{Quality}

Quality improved significantly for all metrics under IHC except for prescribing $\beta$-blockers for patients after myocardial infarction (Table 5 ). Most prevention measures show substantial improvements, particularly those with low levels of compliance in 2007.

\section{DISCUSSION}

The Illinois Medicaid primary care case management program was associated with substantial cost and utilization reductions compared to projections, and with significant improvement of quality. Cost savings estimates are consistent with the direction and magnitude of the state's own internal evaluation but with more clarity as to the categories of savings and with important adjustments for program growth. ${ }^{2}$ Adjusted savings estimates were more than $\$ 750$ million for IHC and YHP over 4 years. The estimate of nearly $\$ 1.5$ billion in overall Medicaid savings likely underestimates true savings, since we used projected annual growth rates substantially lower than those estimated by the Kaiser Family Foundation. ${ }^{14}$ Savings nearly doubled in each of years 3 and 4 .

Based on Centers for Medicare \& Medicaid Services data, Connecticut, Georgia, Kansas, and Texas are reasonable comparison states for the same period, 
Figure 1. IHC and YHP Adjusted per-member-per-month cost trends.

IHC Actual vs. Projected PMPM Cost, 2004-2010

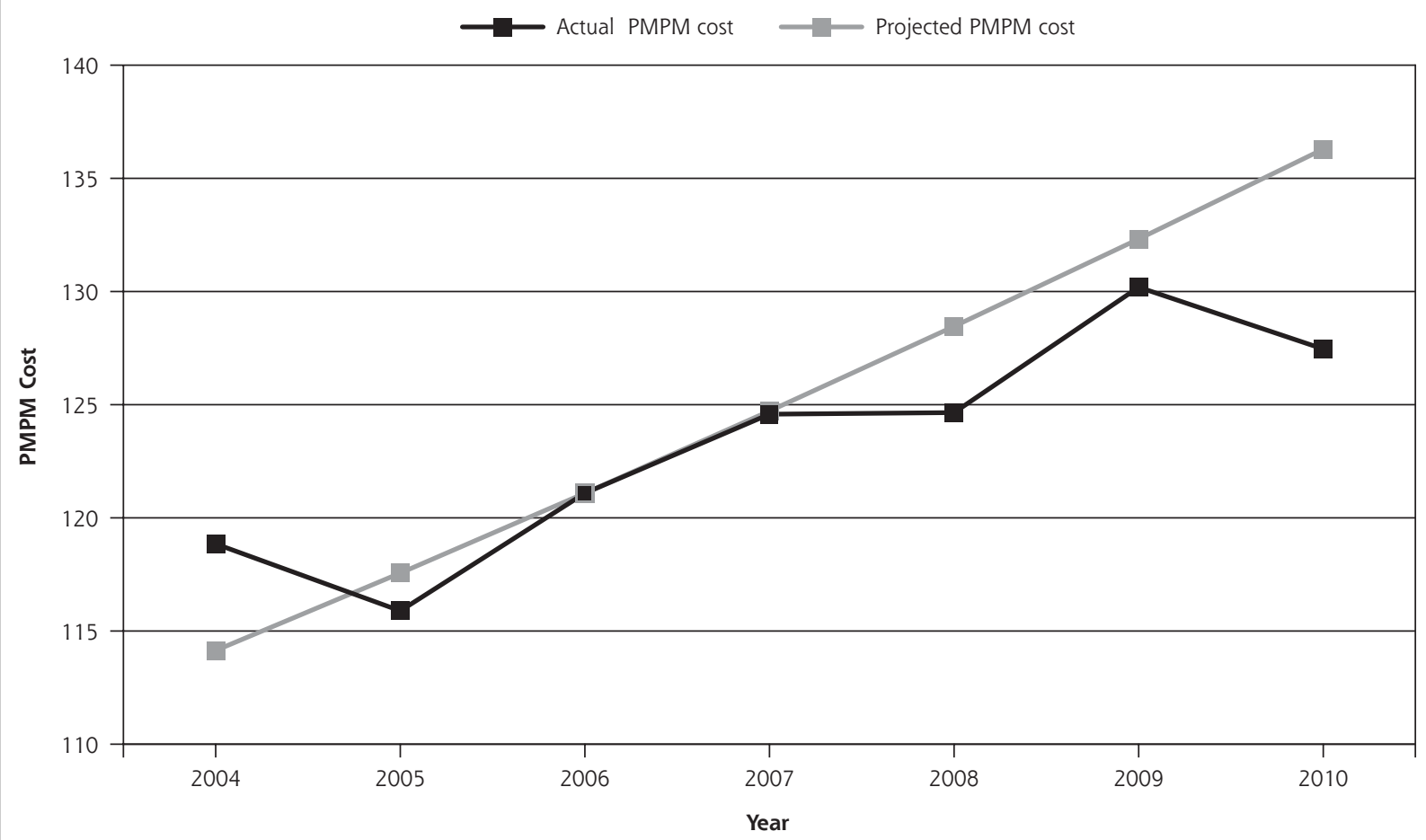

YHP Actual vs. Projected PMPM Cost, 2004-2010

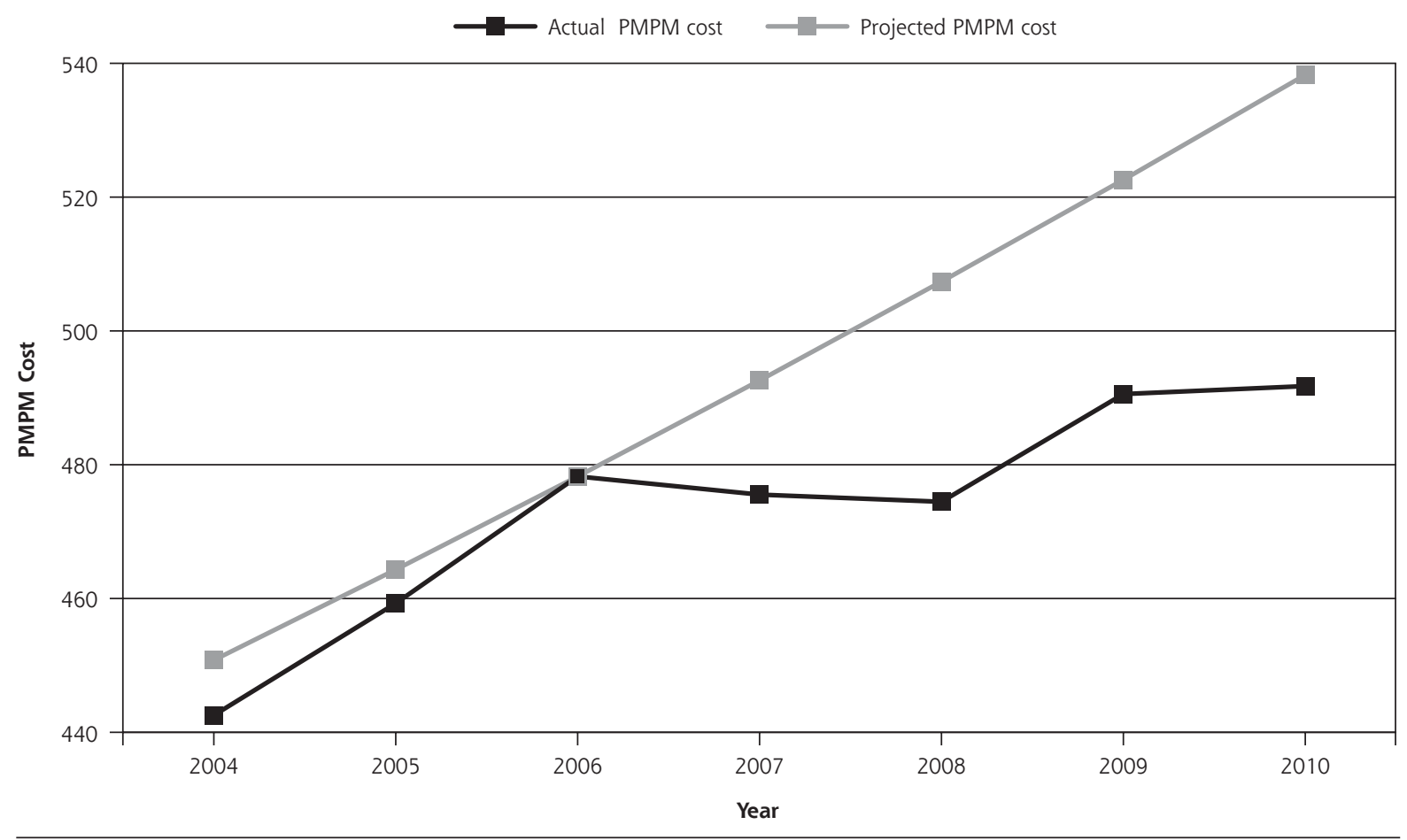

$\mathrm{IHC}=$ Illinois Health Connect; YHP = Your Healthcare Plus; PMPM = Per member per month.

Note: IHC costs prior to 2006 are estimated based on costs for enrolled Medicaid patients who would have met IHC eligibility requirements. 
Table 4. Changes Within Selected Illinois Medicaid Cost Categories, 2010 vs Projected

\begin{tabular}{lcrrr}
\hline Cost Category & Medicaid & IHC & YHP & Other \\
\hline Clinic, \% & 32.57 & 45.70 & 24.89 & 13.48 \\
Inpatient, \% & -30.27 & -22.66 & -24.17 & -32.27 \\
Prescription, \% & -9.88 & -5.48 & 0.65 & -19.44
\end{tabular}

$\mathrm{IHC}=$ Illinois Health Connect; YHP $=$ Your Healthcare Plus.

Table 5. Quality Measure Changes 2007-2010 for Illinois Health Connect Patients

\begin{tabular}{|c|c|c|c|}
\hline Quality Measure & Year & $\begin{array}{l}\text { Appropriately } \\
\text { Treated, \% }\end{array}$ & $\begin{array}{c}\text { Change, } \\
\%\end{array}$ \\
\hline \multirow[t]{2}{*}{ Diabetes nephropathy screen } & 2007 & 80.4 & \multirow{2}{*}{8.9} \\
\hline & 2010 & 87.5 & \\
\hline \multirow[t]{2}{*}{ Diabetes annual Hemoglobin $A_{1 c}$} & 2007 & 63.9 & \multirow{2}{*}{23.4} \\
\hline & 2010 & 78.9 & \\
\hline \multirow[t]{2}{*}{ Diabetes retinal eye examination } & 2007 & 26.0 & \multirow{2}{*}{51.7} \\
\hline & 2010 & 39.5 & \\
\hline \multirow[t]{2}{*}{ Any annual well-child visit } & 2007 & 81.0 & \multirow{2}{*}{10.5} \\
\hline & 2010 & 89.5 & \\
\hline \multirow{2}{*}{$\begin{array}{l}\text { Ischemic vessel disease with } \\
\text { annual lipid profile }\end{array}$} & 2007 & 50.6 & \multirow{2}{*}{34.7} \\
\hline & 2010 & 68.1 & \\
\hline \multirow[t]{2}{*}{ Mammogram } & 2007 & 13.6 & \multirow{2}{*}{87.4} \\
\hline & 2010 & 25.5 & \\
\hline \multirow{2}{*}{$\begin{array}{l}\text { Postacute myocardial infarction } \\
\text { taking } \beta \text {-blocker }\end{array}$} & 2007 & 70.7 & \multirow{2}{*}{-13.7} \\
\hline & 2010 & 61.1 & \\
\hline \multirow[t]{2}{*}{ Asthma control medication } & 2007 & 47.1 & \multirow{2}{*}{6.2} \\
\hline & 2010 & 50.0 & \\
\hline \multirow[t]{2}{*}{ Cervical cancer screening } & 2007 & 13.2 & \multirow{2}{*}{65.7} \\
\hline & 2010 & 21.9 & \\
\hline \multirow[t]{2}{*}{ Colonoscopy } & 2007 & 4.8 & \multirow{2}{*}{77.2} \\
\hline & 2010 & 8.6 & \\
\hline
\end{tabular}

order to understand outcome differences. Interstate collaboration of this kind would help states learn from each other and possibly avoid deleterious policy decisions.

Reductions in inpatient services explain the bulk of savings and utilization changes, although there were also substantial reductions in emergency department visits and associated admissions. We also found improvements in most quality measures for IHC enrollees. These gains in efficiency and quality were associated with increased outpatient care, most of it in primary care. We were not asked to evaluate either YHP or the "Other" group but felt that it would be disingenuous to not include them since we had the data. We also felt that they might offer contrasting outcomes that would reinforce the likelihood that the associations we might find would be related to the interventions. That there were reductions in all three Medicaid groups appropriately raises concerns about secular trends. We were compelled to talk with stakeholders about potential secular trends vs spillover of the interventions. The substantiality of the outcome differences over time and lack of similar changes in other states suggest that cost and utilization changes across all three groups were a reflection of spillover of the intervention rather than secular trends. A recent study demonstrates that there are measureable spillover effects for all patients when practices make general changes for select patients. ${ }^{18}$

The association between increased out-

since all had primary care case management requirements, all involved PMPM payments, all required HEDIS measures of their primary care case management programs, and all had medical home or health home demonstrations in place or under development. ${ }^{16}$ Despite similarities, Illinois' overall per-member-peryear Medicaid costs trended substantially lower than those of these other 4 states (Figure 2). ${ }^{17}$ It is difficult to know exactly why the cost trends for these states were so radically different from that of Illinois despite having some of the same Medicaid reforms. The differences may be related to differences in timing of implementation of common primary care case management elements, differences in how these were implemented, or missing elements, such as academic detailing, access to registries, or quality measure comparisons. ${ }^{16}$ The differences speak loudly to the need for states to compare their policy and implementation differences in patient clinical care and decreased inpatient costs and emergency care is consistent with findings in related programs. ${ }^{19-22}$ The Vermont Blueprint for Health multi-payer model was associated with $22 \%$ inpatient cost reductions in the second year of that experiment. ${ }^{19} \mathrm{~A}$ Rhode Island-mandated increase in primary care spending by commercial insurers led to a $23.2 \%$ increase in primary care spending between 2007 and 2011. The Rhode Island Insurance Commissioner reported that this was associated with a $17.6 \%$ reduction in total spending (a 14 -fold relative difference). ${ }^{22}$ Enrollment expansion brought in a host of healthier patients, which is typical and required adjustment of our findings. ${ }^{23}$

Our findings have important policy implications for related demonstrations. ${ }^{24}$ In 2010, there were 26 multi-stakeholder PCMH pilots in 18 states covering 5 million patients, with another 68 planned. ${ }^{25}$ Nearly 
every federal health agency is supporting $\mathrm{PCMH}$ demonstration projects. ${ }^{26}$ More light needs to be shed on the early outcomes of these PCMH experiments to inform policy makers' fiscal decisions in these tough budgetary times. Indiana recently published a related study of a Medicaid chronic disease management plan that had been implemented in regional phases to allow for cohort comparisons as well as repeated measure analysis. ${ }^{27}$ Oregon took this one step further, truly randomizing Medicaid expansion to evaluate outcomes. ${ }^{9}$ Figure 2 makes the point that states can introduce innovations with good intentions, but how they are implemented and evaluated are important to understanding whether and how they matter.

\section{Limitations}

Caution is necessary in interpreting repeated-measures studies with comparable cohorts. In addition, our use of administrative data is a limitation due to possible errors in the claims records or false understanding of often complicated claims data. We worked closely with analysts in the Illinois HFS, conducting iterative quality checks to reduce the likelihood of errors. The greater concern is that there may be other explanatory factors we could not measure. This is one viable explanation for why Medicaid overall enjoyed cost reductions. Another explanation, however, may be that all Medicaid patients received care in the same clinics as IHC and YHP beneficiaries, where they were exposed

\section{Figure 2. Change in average Medicaid per-member-per-year costs for Illinois and comparison states.}

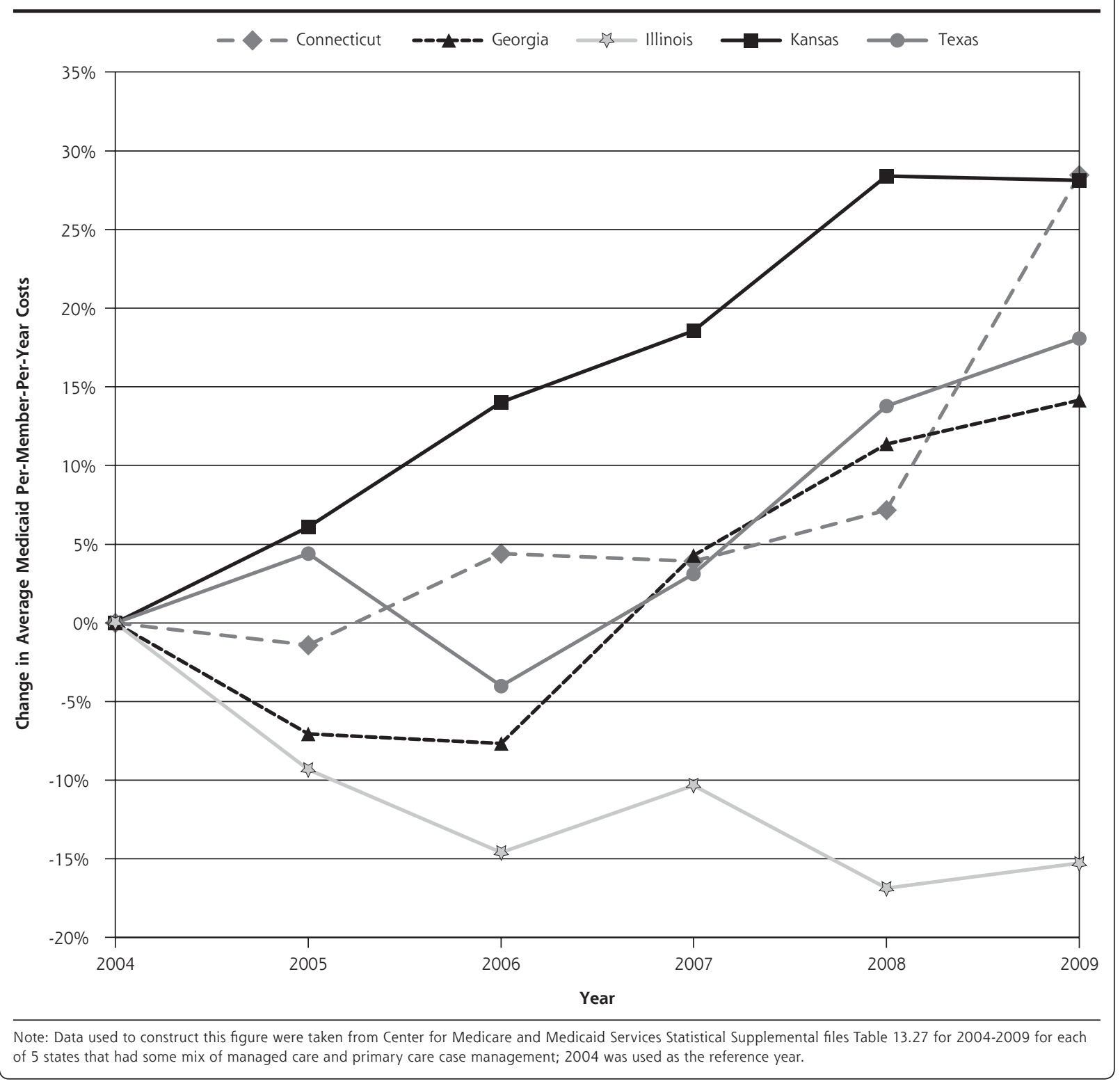


to similar effects. Another important limitation is that we could not do further analysis on the uptake of IHC and YHP features by practices. That would have better explained associated outcomes and potentially helped explain why Illinois' outcomes were different from those in comparison states. This limitation also leaves physicians without specific information about how to judge whether or not to participate in future Medicaid experiments.

We cannot declare specific causal relationships. Although measurable new investments were made in primary care, and IHC practices were afforded support systems like those of accountable care organizations (regular quality measure reporting, access to all claims data, panel definition, and local care management), we have no information about specific changes practices made. And while the improved outcomes for other Medicaid beneficiaries may be related to their care in IHC/YHP practices, neither program offered direct support for these patients. It is likely that these practices did not differentiate between Medicaid patients, but that remains an assumption. We cannot say why Illinois's YHP beneficiary outcomes were robust compared to those for case management generally, except that its outcomes were more like those where patients and practices are strongly related. ${ }^{28}$ Finally, we want to acknowledge that our search for related, single-state policy and practice transformation efforts may have suffered from publication bias, potentially missing examples of related state experiments that did not produce similar outcomes.

\section{CONCLUSIONS}

Illinois Health Connect, a Medicaid primary care case management program with features similar to those of patient-centered medical homes and accountable care organizations, was associated with cost reductions, improved utilization patterns, and generally improved quality. Specifically, IHC and the YHP program were associated with (1) substantial increases in outpatient services ${ }_{i}(2)$ larger decreases in inpatient and emergency services; (3) a reduction of total costs vs projections; and, (4) substantial improvements in most preventive and chronic care quality measures. Improvements may have been blunted by the influenza epidemic of 2009. Cost reduction rates were still rising in the fourth year, nearly doubling each year, suggesting a long maturation period or a lag in realizing cost reductions. These findings are consistent with related studies, particularly in the relationship between increased primary care expenditures and reduced inpatient and emergency department costs and utilization, and with other PCMH demonstration projects. $8,20,22,24$
There were likely spillover effects for Medicaid beneficiaries beyond the IHC population, consistent with a recent accountable care demonstration. ${ }^{18}$

The Illinois legislature partially dismantled these programs to slash $\$ 3$ billion from the state budget in a single year. Policy makers are trying to solve access and fiscal concerns, not run experiments; however, this approach can sabotage their intentions, and beneficial programs, when new fiscal pressures arise. States should take away several points from this short-lived experiment:

- Enhanced fee-for-service was associated with increased physician participation in Medicaid and improved beneficiary access.

- Blended payments that include capitation and robust quality rewards were associated with reduced inpatient and emergency department costs and utilization.

- Medicaid contractors can support community-based practices with feedback on quality, population measures, and patient resources almost the way an accountable care organization supports its member practices.

- It may take 3 or more years to reveal the full effects of insurance and practice transformation experiments.

- Evaluations need to account for epidemics or other environmental factors that may inflate or deflate outcomes.

- Disease and care management programs may work best when they have close relationships with patients and providers.

- State-based experiments need embedded evaluation to avoid bad policy decisions in the absence of data.

To read or post commentaries in response to this article, see it online at http://www.annfammed.org/content/12/5/408.

Key words: Medicaid; patient-centered medical home; primary care; health services research; utilization; health care economics; health care reform

Submitted November 10, 2013; submitted, revised, April 29, 2014; accepted May 20, 2014.

Funding support: This study was supported by The Commonwealth Fund, a national, private foundation based in New York City that supports independent research on health care issues and makes grants to improve health care practice and policy.

Disclaimer: The views presented here are those of the authors and not necessarily those of The Commonwealth Fund, its directors, officers, or staff. The information and opinions contained in research from the Graham Center do not necessarily reflect the views or policy of the American Academy of Family Physicians.

Acknowledgments: The authors wish to thank Dr Margaret Kirkegaard, Medical Director, Illinois Health Connect, Automated Health Systems, for her clarification of IHC elements and provision of internal reports on uptake of program components. 


\section{References}

1. Rhodes KV, Bisgaier, J. Measuring Pediatric Access to Subspecialty Care by Insurance Status in Cook County: Final Report. Pittsburg, PA: Penn School of Social Policy \& Practice: University of Pennsylvania; 2011.

2. Illinois' care management programs save $\$ 320$ million in successful third year [news release]. Springfield, IL: Illinois Department of Health and Family Services; April 28, 2010. http://www3.illinois.gov/PressReleases/ShowPressRelease. cfm?SubjectID =19\&RecNum=8406. Accessed Nov 10, 2013.

3. National Academy for State Health Policy. Medical Home \& PatientCentered Care. http://www.nashp.org/med-home-map. Published 2012. Updated January 19, 2013. Accessed Nov 10, 2013.

4. Weil A. How far can states take health reform? Health Aff (Millwood). 2008;27(3):736-747.

5. Long SK, Stockley K, Dahlen H. Massachusetts health reforms: uninsurance remains low, self-reported health status improves as state prepares to tackle costs. Health Aff (Millwood). 2012;31(2):444-451.

6. Long SK, Masi PB. Access and affordability: an update on health reform in Massachusetts, fall 2008. Health Aff (Millwood). 2009;28(4):w578-w587.

7. Clark CR, Soukup J, Govindarajulu U, Riden HE, Tovar DA, Johnson PA. Lack of access due to costs remains a problem for some in Massachusetts despite the state's health reforms. Health Aff (Millwood). 2011;30(2):247-255.

8. Harbrecht MG, Latts LM. Colorado's Patient-Centered Medical Home Pilot met numerous obstacles, yet saw results such as reduced hospital admissions. Health Aff (Millwood). 2012;31(9):2010-2017.

9. Allen H, Baicker K, Finkelstein A, Taubman S, Wright BJ; Oregon Health Study Group. What the Oregon health study can tell us about expanding Medicaid. Health Aff (Millwood). 2010;29(8):1498-1506.

10. Kliff S. Can Oregon save American health care? Washington Post. January 18, 2013. http://www.washingtonpost.com/blogs/ wonkblog/wp/2013/01/18/can-oregon-save-american-health-care/. Accessed Nov 10, 2013.

11. Patient Centered Primary Care Collaborative. Defining the Medical Home. http://www.pcpcc.org/about/medical-home. Accessed August 20, 2014.

12. Agency for Healthcare Research and Quality. Patient Centered Medical Home Resource Center: Defining the PCMH. http://pcmh. ahrq.gov/page/defining-pcmh. Accessed July 21, 2014.

13. Bureau of Labor Statistics. Archived Consumer Price Index Detailed Report Tables: Medical Care Expenditure Component 2004-2010. October 30, 2013. http://www.bls.gov/cpi/cpi_dr.htm\#2012. Accessed Nov 10, 2013.

14. Kaiser Family Foundation. Illinois. Average annual growth in Medicaid spending, FY1990-FY2010. January 24, 2012. http://kff.org/ medicaid/state-indicator/growth-in-medicaid-spending/. Accessed July 21, 2014.

15. Martin AB, Lassman D, Washington B, Catlin A; National Health Expenditures Accounts Team. Growth in US health spending remained slow in 2010; health share of gross domestic product was unchanged from 2009. Health Aff (Millwood). 2012;31(1):208-219.
16. Kaiser Commission on Medicaid and the Uninsured. A Profile of Medicaid Managed Care Programs in 2010: Findings from a 50-State Survey. Washington, DC: The Henry J. Kaiser Family Foundation; 2011. http://kaiserfamilyfoundation.files.wordpress. com/2013/01/8220.pdf. Accessed May 27, 2013.

17. Center for Medicare \& Mediciad Services. Table 13.27 - Medicaid Payment per Person Served (Beneficiary), by Type of Service and Area of Residence, 2008 - 2011 Editions. Baltimore, MD: CMMS; 2008-2011.

18. McWilliams JM, Landon BE, Chernew ME. Changes in health care spending and quality for Medicare beneficiaries associated with a commercial ACO contract. JAMA. 2013;310(8):829-836.

19. Bielaszka-DuVernay C. Vermont's blueprint for medical homes, community health teams, and better health at lower cost. Health Aff (Millwood). 2011;30(3):383-386.

20. Nielsen ML, Langner B, Zema C, Hacker T, Grundy P. Benefits of implementing the primary care patient-centered medical home: a review of cost $\&$ quality results, 2012. http://www.pcpcc.org/sites/ default/files/media/benefits_of_implementing_the_primary_care_ pcmh.pdf. Accessed Jan 24, 2013.

21. Takach M. Reinventing Medicaid: state innovations to qualify and pay for patient-centered medical homes show promising results. Health Aff (Millwood). 2011;30(7):1325-1334.

22. Rhode Island Office of the Health Insurance Commissioner. Primary care spending in Rhode Island: health insurer compliance $\mathcal{E}$ initial policy effects. http://www.ohic.ri.gov/documents/Insurers/Reports/2012\%20Primary\%20Care\%20Spend/Primary\%20 Care\%20Report_FINAL.pdf. Published September 2012. Accessed Aug 20, 2014.

23. Chang T, Davis M. Potential adult Medicaid beneficiaries under the Patient Protection and Affordable Care Act compared with current adult Medicaid beneficiaries. Ann FamMed. 2013;11(5):406-411.

24. Peikes D, Zutshi A, Genevro J, Smith K, Parchman M, Meyers D. Early evidence on the patient-centered medical home. 2012. http://pcmh. ahrq.gov/sites/default/files/attachments/Early\%20Evidence\%20on\%20 the\%20PCMH\%202\%2028\%2012.pdf. Accessed July 22, 2014.

25. Bitton A, Martin C, Landon B. A nationwide survey of patient centered medical home demonstration projects. J Gen Intern Med. 2010;25(6):584-592.

26. Agency for Healthcare Research and Qualilty Patient Centered Medical Home Resource Center. Federal PCMH activities. 2012. http:// pcmh.ahrq.gov/portal/server.pt/community/pcmh__home/1483/ pcmh_federal_pcmh_activities_v2. Accessed Jan 24, 2013.

27. Katz BP, Holmes AM, Stump TE, et al. The Indiana Chronic Disease Management Program's impact on medicaid claims: a longitudinal, statewide evaluation. Med Care. 2009;47(2):154-160.

28. Peikes D, Chen A, Schore J, Brown R. Effects of care coordination on hospitalization, quality of care, and health care expenditures among Medicare beneficiaries: 15 randomized trials. JAMA. 2009; 301(6):603-618. 